\title{
Attempting Discussion of Mythological Concepts’ Determinism*
}

\author{
YE Shu-xian \\ Shanghai Jiaotong University, Shanghai, China
}

\begin{abstract}
Current sciences fail in understanding the future trends of human beings' behaviors and cultures. From the hunting tribes to the agricultural society, the civilized country, and then to the industrial society, none of these developments is the results of human beings' reasonable proposal. The human beings are "developed”, i.e. pushed forward by certain invisible forces. As being cultural, they are dominated by their cultural concepts. To explore the source of every civilization's concepts, the formation history of its mythological concepts during the pre-historic period or at the beginning of its civilization shall be studied first. By interpreting the first literature works at the beginning of western civilization, the temporary mythologists reveal the rule that mythological concepts dominate the ritual behaviors and narrative expressions. This paper interprets the historical narratives in Records of the Grand Historian: Annals of the First Emperor of Qin, to reproduce the concepts that dominate China's national rulers, present the theory of Mythological Concepts’ Determinism, and correspond to the counter-force of ideology put forward by Friedrich Engels in his later years and the religious concepts' determinism by Max Weber, so as to illustrate the mythological concepts' function as the prototype code of ideology, and refer to a common and effective directory approach of social science studies.
\end{abstract}

Keywords: human beings being developed, mythology, mythological concepts, determinism, historical causal theory

\section{Chapter One Decode Human Beings’ Behaviors}

What elements on earth determine the human beings' behaviors? Why residents on the old continents abandoned the hunting life around 10,000 years ago, and started to try two new styles of production and living — farming and livestock raising? Without any forecasting or any reasonable planning, human beings are "agricultural”, turning from hunters chasing beasts to farmers planting crops. Soon after they learned the techniques of farming and livestock raising, they were "civilized". It only took a few thousand years from the starting of agriculture in the near-east to the building of cities and high pyramids along the Nile bank. None of these are forecasted or presupposed, so we say human being were "civilized". Various races may create many inventions in certain fields, but generally, they are pushed forward by a kind of invisible force. The same is true for the capitalist industrialization several thousand years ago, and the near international internetization and

\footnotetext{
* Acknowledgements: This paper is supported by China National Find of Social Sciences "The Theory and Method of Literary Anthropology".

YE Shu-xian, Chair Professor, Shanghai Jiaotong University, China. Director and Professor of Comparative Literature, Chinese Academy of Social Sciences. Editor in Chief of "The Series of Anthropological Explanation of Chinese Classics". His research field covers Chinese Literary Anthropology, Cross-culture research, Chinese classical culture and Comparative Literature.

This paper is translated by Wu Juan and Liu Wan-er. WU Juan, Lecturer of Beijing Institute of Technology, China. LIU Wan-er, Graduate of Beijing Institute of Technology, China.
} 
globalization, neither of which resulted from personal or group design. Until today, we have to admit that, though acknowledged ourselves as being rational, we human beings have no prophetic visions. Our ancestors are more humble and cautious, so they leave all prophesy to oracles in the temple or clergies, such as the shaman, witch, seer or augur. However, the modern people, abandoning these ancient believes, become arrogant, and think themselves as the paragon of the universe, who can do things as they want and even change the world. But after experiencing many world wars, and seeing millions of fellowmen die unnatural deaths, they come to realize that: up to now, human beings are still unable to predict their own fate, nor dominate the future of the world. Even with so many economists in the world, none of them can offer accurate predictability of a financial crisis. We can say, the secret of human race and their culture is the most difficult Sphinx's riddle. It requires the scholars' further efforts to get at the answer.

Without a theory to explain the humans' behaviors and the consequences, we have to say that: the philosophical proposition that "human beings are rational" only makes sense in very limited conditions. Research on the inner mechanism that drives humans' behaviors is the most advanced subject of humanities and social sciences, which urgently needs systematic academic studies and multidisciplinary cooperation. The school of literary anthropology hopes to explore this subject on both the theoretic and practical level and make some contribution through integrating the real occurrences of Chinese culture. The current focus is to concentrate on interpreting the causality of Chinese civilization from mythological concepts, to behaviors, and then back to historical incidents.

According to current academic achievements, in explaining humans' behaviors, the theory that can clearly explain this causality is cultural determinism: special cultural traditions determine the general behaviors of the members of this cultural group. When we ask why: what the ancient Egyptian civilization in the North Africa created is the Great Pyramids, what the ancient Indian civilization created is Hinduism and Buddhist monastic life, while, what the Chinese civilization created is the Great Wall and the imperial seal. To answer all these questions, we need to see each culture from the inside to understand its inner cultural rules. Only in this way will our interpretation be specific and clear. This also explain why the definition of cultural anthropology turns from the "the science of man" in the early 19th century to "The Interpretation of Cultures" (the name of a book written by Clifford Geertz). What it explores changes from the general rule of human cultures' evolution applying to all cultures to understanding the special characteristics of every local culture one after another. The concept of "man" finally becomes relatively concrete instead of being highly abstract. All secrets of the ancient Chinese why they were different from the ancient Egyptian and the Greek need to be re-known in the large view of global civilization. The same as the differences of civilizations, the differences of cultures also requires us to appeal to the deep conceptual structure, which is like the genes of live beings, to find an effective answer.

\section{Chapter Two From “Mythology-Rites” to the Determinism of Mythological Concepts: Walter Burkert and Richard Broxton Onians}

As the joint point of literature and cultural anthropology, mythology is attached great importance by both sides. So it has become the most studied field of cultural anthropology. The teachers and students of literature usually focus on the literary property of mythology and excel in analyzing the characters, themes, motifs, linguistic rhetoric and style of mythological narrations; while, the teachers and students of anthropology focus on the mythology and rites as a cultural combination, its working mechanism and its function in specific cultural group (society). For that matter, literature is just one of the external expressions of mythology, and 
what determines is the hidden values, driving forces and operating mechanism. It is like a puppet show, what acts and performs on the stage are the puppets, however, what dominates these puppets are the invisible dominator. The current research has found the dominator hidden behind the historical puppet show, i.e. the mythological belief and concepts dominating the mythological imagination and narration.

Without the mythological values of regarding gold as holy, the ancient Greek won't have the imaginative narration of gold age and gold apple. Similarly, without Chinese mythological values of worshiping jade as holy and immortal, Chinese will not have the mythological history of jade stories, including Bian He's presenting beautiful jade to the kings, Bi of He (和氏璧, Bi-a piece of jade with hole in center), and Wan Bi Gui Zhao (完璧归赵, literal meaning-Bi came back to Zhao sound and safe, extended meaning-to return a thing intact to its owner), let alone First Emperor of Qin's imperial seal and Emperor Wu of Han's funeral rites of being buried with gold and jade clothes on. The next tasks seem more and more clear: turning from the literary mythological research to the research of mythological concepts' genetics, which is similar to the archaeology of knowledge in the domain of western civilization by Michel Foucault, or "the archaeology of mythological concepts”. Due to this, the scope and subject of current research extends from ancient mythological stories in written form to the pre-writing prehistoric jade articles for worshiping purposes. What this brings about is the redefinition of a pair of terms-great tradition and small tradition - the great tradition means the tradition before or beyond the written record, and the small tradition means the tradition of written records. Through the advantages of quadruple evidences, we hope to reconstruct the long-lost great tradition of cultural texts, and then perfectly combine the great tradition that has no written words and the small tradition that has written records, so that we can get further more knowledge about the history of civilization which our predecessors do not get.

The western scholars who studied the origin of literature once focused on the ancient Greek literature, hoping to find the secrets of "The Birth of Tragedy" (the name of a book written by Friedrich Nietzsche), which later formed a school of theory in the 20th century, i.e. the Myth and Ritual School, who thinks that Greek drama originated from religious rites, and the original drive behind performances is god worshiping and religious belief, not aesthetic or entertainment. Terms like Dionysian Spirit and Apollo Spirit in the field of literature entered the field of anthropology. Viewed from this, the research of mythic literature gave way to the research of mythic conceptual forces, i.e. understanding the motivations behind ancient people's behaviors through reconstructing the mythological concepts, and then interpreting the dominating rules of the whole culture, instead of the expression rules of literary texts only.

One of the theoretic heritages left by the Myth and Ritual School is the differentiation of the order of myths and rites, i.e. which one came first in the time line. Viewed from the evolution facts that behaviors came before the languages, it seems that rites determined the myths; but viewed from that human beings are conceptual, and concepts determine behaviors, mythic concepts determine rites. The more fundamental and forceful element is the concepts that drive the rites. Walter Burkert studied this from the perspective of cultural anthropology and gained a lot of achievements. He once was invited to be the visiting professor of Classical Studies. One after another of his works in German were translated into English and widely read. Due to his significance in leading Greek mythology out of the field of literature, I listed three books of his into the key project of Chinese Academy of Social Sciences-Works Translated for the "Mythology Research to Explore the Origin of Chinese Civilization”. The Chinese version of these books has not been published yet because of 
copyright consideration. The article From Hunting to Sacrifice: Analysis of Greek Funerary Rituals in this column was selected from Burkert's influential works Homo Necans: the Anthropology of Ancient Greek Sacrificial Ritual and Myth. In Chapter One of this book, the author gave the example of a funeral described in The Iliad, the first works of ancient Greek or even the whole western literature, to illustrate how literature becomes an important medium for anthropologists to interpret funerary rituals. What kind of concepts dominated the whole process (transformation, transition and substitution) of the great tradition of hunting's turning into Greek little tradition of funerary ritual? It's the mythological concepts.

The Origins of European Thought by Richard Broxton Oians was a great book published by Cambridge University Press more than half a century ago, which is not widely known by Chinese scholars. The author had a good knowledge of Greek and Roman literature, and specially concentrated on looking for the religious origin of the thought history in the ancient mythological literature. He thought that all philosophies and sciences originated from the religious beliefs at the beginning of civilizations. His research in this field was very attractive: "those are the basic beliefs about life, thought and fate, which determine everyone's words and actions." It's not just for the Greek. In some sense, what we are digging is the root of civilizations in Europe and other places. I think, the basic beliefs we trace in Greek and Roman languages and the earliest literary works are also shared by the Germanic people, the Celts, and other races. At least in some cases, these beliefs have already been widely accepted in the Paleolithic age. They can explain people's weird behaviors at that time, which also exist in modern idioms and phrases in the way we are not aware of." ${ }^{1}$ These unknown mythological concepts are harder to recognize by later generations. They are like the cultural codes silently hiding behind historical events, awaiting the anthropologists to decode. As Claude Levi-Strauss, the representative of structuralist anthropology put it, the basic difference between anthropology and history is that, history studies things people are aware of, but anthropology explores things people are not aware of. For Marxists, things unaware of in culture and society are the deep structure of productive forces and relations. For structuralists, things unaware of in culture are conceptual structure, such as conceptual logic of binary oppositions etc.

How on earth should we look for the determinative elements of humans' society—by way of material production or conceptual morphology? The main direction of research in 19th century was by way of material production. Since 20th century, due to the influence of Max Weber's book The Protestant Ethic and the Spirit of Capitalism, the research turns to the conceptual morphology as the mainstream. This paper hopes to continue the discussion on this important question, and explores the inheritance, innovation and advances of the Marxist theories.

\section{Chapter Three The Historical Causality in Records of the Grand Historian: Annals of the First Emperor of Qin}

Both the previous two examples to illustrate how mythological concepts dominate the behaviors of historical figures are related to the first works of the western civilization-Homer's Epic. No grand narration works like Homer's Epic was left at the beginning of literary history of Chinese civilization. The following will choose part of the historical narration in the first Chinese comprehensive history book, i.e. Records of the Grand Historian: Annals of the First Emperor of Qin, which talks about the behaviors and incidents of the

\footnotetext{
${ }^{1}$ Onians, Richard Broxton. The Origins of European Thought. Cambridge: At the University Press, 1954, p. 1.
} 
supreme nation ruler, to illustrate the potential dominance of mythological concepts, and mark it as the Chinese version of Mythological Concept Determinism.

If we want to know what happened in the world in certain year, we can refer to Chronology on Chinese and Foreign History written by Jian Bozan, Qi Si et al. On page 99, it listed several events happened in the year of 211 B.C. respectively China, Carthage, Roman, etc.:

China, 211 B.C., the 36th year of the First Emperor of Qin's reign

People in the East Town carved "The First Emperor of Qin dies and the state divides" in a meteorolite. All the citizens living nearby the meteorolite was killed by (the First Emperor of Qin). Thirty thousand families were forced to move to Yuzhong, north to the Yellow River.

\section{Foreign-Roman}

Syracuse was defeated by and surrendered to Roman. The rest of Sicily also returned to Roman. ${ }^{2}$

The historians wrote this briefing according to the around-100-word narration in Records of the Grand Historian: Annals of the First Emperor of Qin. To know the causality of this event, the original text is given in the following:

The Mars invaded the Scorpio. A meterolite fell onto the East Town, and became a stone on the earth. People carved "The First Emperor of Qin dies and the state divides" in it. The Emperor heard of it and sent an official to investigate it. Nobody admitted his guilt. So the Emperor ordered to kill all the people living nearby the stone and burned the stone. The Emperor was unhappy. He ordered the doctor to write Xian Zhen Ren Shi (a poem to praise the Emperor), so that when he toured around the country, the musicians can play and sing it. Till the autumn, a messenger passed by Pingshu Road, Huayin Town. Someone holding a Bi (piece of jade with hole in center) stopped the messenger and said, "Please bring this to Mr. Hao Chi for me." He also said, "this year, the ancestral Long will die.” The messenger asked him why, but he disappeared in a second, only leaving the Bi. The messenger took back the Bi and told the Emperors all he experienced. For quite a while, the Emperor said nothing, and then he said, "Ghosts in the mountains can only foresee things in the next year." Later, he said, "the ancestral Long means the ancestor of people.” He asked the jade department to inspect the $\mathrm{Bi}$, which was identified as the very Bi the Emperor himself dropped in the river when he toured the country in the 28th year of his reign. So the First Emperor practiced divination to it, and the oracle said that it was good to migrate. So the he ordered to move 30,000 families to Yuzhong, north to the Yellow River. All members of these families are entitled as the first class officials. ${ }^{3}$

The $36^{\text {th }}$ year of the First Emperor of Qin was also 211 B.C., which is the 10th year Ying Zheng, King of Qin, united China and founded a big empire. According to the tradition, there would be a lot of celebrations in the 10th year. But in Annals of the First Emperor of Qin, Sima Qian talked not that much about this year's events - only two of them were related in this paragraph: first, the prediction carved in the meteorolite which brought about the deaths of many families. The sentence that "So the Emperor ordered to kill all the people living nearby the stone" clearly shows the cruelty of this tyrant and his fear. Second, the mysterious message conveyed by the $\mathrm{Bi}$ brought by the immortal. $\mathrm{Bi}$ is like the oracle in the Apollo temple in the Greek myths! Eight years ago, Ying Zheng was stuck in a storm when crossing the river. He threw this Bi into the river which protected him to cross the river sound and safe. Eight years later, this Bi magically came back to the Emperor.

\footnotetext{
2 Jian, Bozan. Chronology of Chinese and Foreign History. Shanghai: Zhonghua Book Company, 1961, p. 99.

${ }^{3}$ Sima, Qian. Records of the Grand Historian. Beijing: Zhonghua Book Company, 1982, p. 259.
} 
He ordered the officials in the jade department and divined it personally. As a result, such historical event happened- - "he ordered to move 30 thousand families to Yuzhong, north to the Yellow River.” If we ask why the Emperor did these two big actions in this year-one slaughter of the innocent and one migration of many families - both of them resulted from the mythological concepts the ruler believed. The reason to kill is directly illustrated in the text - to punish the fabricator of unlucky augury. The stone on the earth came from the sky, which gave people the mythological association that it was the media of the heaven's will. To eliminate the spiritual threat brought by this meteorolite with unlucky augury, what Ying Zheng could do was only to make a slaughter. The reason to move 30 thousand families was a bit more complicated. It came with the mythological message brought by a lost-then-found Bi: "God of River left Bi to God of Hao Chi, to tell the First Emperor of Qin that his reign will end. And the River of Qin was loyal to its King. So, since its King is going to die, God of River first came to tell him.” ${ }^{4}$ The prediction ability of God of River is limited, only able to foresee the second year. Faced with this mysterious message, Ying Zheng himself didn't understand, so he divined it to ask the heaven's will. The result showed that, if he migrated many people, he would be able to turn calamities to blessings. In Annotations to Records of the Grand Historian, Zhang Shoujie of Tang dynasty clearly illustrated that: "he ordered to move 30 thousand family because the divination said that it was good to move people." 20,000 families, with the elders and youngsters, were forced to migrate, just in order to conform to the oracle.

Faced with the fallen meteorolite and the unlucky words inscribed by his people, he kept silent for a long time before he said that sentence, which could be seen as a motto for people at that time: "Ghosts in the mountains can only foresee things in the next year." In other words, the supernatural ghosts' capacity in foreseeing the future has a time limit. What they can see is that of the next year, and not any further. We don't know how Sima Qian knew this concrete and exact sentence when the First Emperor of Qin was encountered with such an event. Maybe, in the West Han dynasty when Sima lived, people still held to the folk belief in this sentence. In Annals of the First Emperor of Qin, narration about the next year (i.e. 201 B.C., the 37th year of the First Emperor's reign) told us the death of the First Emperor in July. So we can hardly be sure that: Sima is writing historical records or mythical legend. Why the "things in the next year" foreseen by the ghost can be so precise and efficacious?

$\mathrm{Bi}$, a round sacrificial jade with a hole in the center, dating from the 6000-year-old Hongshan Culture and 500-year-old Liangzhu Culture, then extending the more-than-2000-year-old Qin dynasty, had lasted for nearly 4000 years. Without understanding the conceptual tradition of jade myths, the later generations are subject to neglect the important roles jades played in ancient historical narrations. Viewed from this, in reading ancient books, we need not only the capability in interpreting the words and characters, but also the reconstruction of a new knowledge concept of the great tradition.

Ying Zheng, the founder of a great united empire, couldn't foresee his fate or the future of the empire's regime. With hope and fear in mind, how he relied on the priests (necromancer, wizards etc) is clearly shown here. The four characters “始皇卜之” (meaning: the First Emperor practiced divination) by Sima Qian let us see the historical tradition after Shang dynasty that the emperors practiced divination by themselves, which was still popular after Qin and Han united China as one. That's the basic reason why we need to restore Chinese

\footnotetext{
${ }^{4}$ Sima, Zhen. Index to Records of the Grand Historian. See in Records of the Grand Historian (Shanghai: Zhonghua Book Company, 1982, p. 259.) by Sima Qian.

${ }^{5}$ Sima, Qian. Records of the Grand Historian. Shanghai: Zhonghua Book Company, 1982, p. 259.
} 
history as mythological history. Some scholars follow the western philosophers as sheep, believing that there is an "Axial Period" in the world history, and various key civilizations experienced the "philosophical revolution" at the same time. If so, how can they interpret things happened in this year of Chinese history?

In fact, under Sima Qian's pen, the First Emperor of Qin had long been worried about the safety of this newly united state. The fundamental motive why he spared no efforts in building the Great Wall was the five unlucky characters said by Lu Sheng, i.e. “亡秦者胡也 (meaning: it will be the tribes from the north who end Qin's regime)”. The Great Wall was built to prevent the invasion of the northern nomadic tribes.

Who was Lu Sheng? At that time, Lu Sheng was a religious character that can speak for the ghosts and gods or pass on their messages. Let's see the selected narrations in Annals of the First Emperor of Qin, about what happened from 215 B.C. to 213 B.C.:

In the 32nd year, the First Emperor went to Jie Shi. He sent Lu Sheng from Yan to visit Xian Men and Gao Shi. He ordered people to set up a monument at the gate of Jie Shi Mountain. So the city was destroyed and the dike was broken. ...so he sent Han Zhong, Hou Gong and Shi Sheng to look for the elixir of life. The First Emperor toured the north and returned to the capital from Shang County. Lu Sheng from Yan came back from the sea. He presented a book with pictures to tell the Emperor about the things of ghosts and gods, saying that "it will be the tribes from the north who end Qin's regime". So the First Emperor ordered the general Meng Tian to take 300,000 soldiers to attack the northern tribes. As a result, the land south to the Yellow river was conquered by Qin.

In the 33rd year, the Emperor sent the once arrested people, the married slaves and businessmen to conquer Luliang area and set up the Guilin, Xiangjun, and Nanhai counties there to be guarded by the relegated officials. Xiongnu in the north-west were driven off. Along the Yellow river, from Yuzhong in the west to Yinshan in the east, 44 prefectures were set up, and walls were built along the river to set up fortresses. The Emperor also ordered Meng Tian to cross the river, conquer Gaoque, Yangshan, and Beijia, and build fortresses to drive off the northern tribes. The relegated officials were migrated to fill the newly-founded prefectures. People were forbidden to worship the Ling star which was in charge of the crops. A comet appeared in the west. In the 34th year, the unjust judges were sent to build the Great Wall and guard the Nanyue area. ${ }^{6}$

Narrations about these two years emphasized the First Emperor's efforts in managing the frontier fortresses in the north and south. Sima Qian quoted On Fault of Qin by Jia Yi, “The First Emperor commanded the construction of the Great Wall to ward off the invasion of Xiongnu. Therefore, neither did the nomadic tribes dare to take cows to pasture nor the warriors dare to revenge by pulling the bow.” Thus the famous Great Wall appeared. The nomadic tribes are Xiongnu in the north. The Emperor put Lu Sheng from Yan in an important position because he excelled in "things of the ghosts and gods". Lu Sheng gave a five-character ("亡 秦者胡也”) oracle through an ancient book with pictures, which was the main cause of Ying Zheng's commanding 300,000 soldiers to attack the tribes in the north and the construction of the Great Wall. We can see that, the First Emperor, who thought himself as being chosen by heaven's will and his achievements and land exceeding the Three Emperors and Five Sovereigns, still couldn't be comfortable in enjoying the peace. He thought highly of any omen that can reflect the heaven's will and the intentions of the ghosts and gods, so that he can draw on advantages and avoid disadvantages. Oedipus, the king of Thebes in ancient Greek was

${ }^{6}$ Sima, Qian. Records of the Grand Historian. Shanghai: Zhonghua Book Company, 1982, p. 259. 
overwhelmingly clever, being the only people who can solve the Sphinx's riddle. But he still couldn't know his own fate, unknowingly killing his father and marrying to his mother. The only man who saw through all these was the King's priest Tiresias, a blind prophet. Similarly, the regime of the King of Qin, Ying Zheng, also needed the priest Lu Sheng to pass on the heaven's will and the intentions of ghosts and gods. The mythological concepts in their beliefs became the foundation of the ruler's reign.

Parallel with jade Bi that represented the heaven's will, the system that the jade imperial seal first created by Ying Zheng symbolizes the national power is also based on the mythological logics of the oneness of man and nature and the unification of the state and the church. In The Emperor and the Assassin, a picture inscribed on a stone in the Han dynasty which was unearthed in Wuliang ancestral temple, Shandong Province, the only magic weapon the Emperor used to threaten the assassin was an imperial jade seal held in his left hand and lifted over his head. The jade seal itself is not only the holy symbolism of luminous bodies in the sky, but also the embodiment of signs that witness the heaven's will, i.e. eight character inscribed in the font of seal character by Li Si, the Prime Minister of Qin: “受命于天, 既寿永昌 (meaning: It’s the heaven’s will that Qin rules the world, and it will last for long and be prosperous)."7 The reality is, the Qin dynasty only lasted for 15 years, with a sharp contrast with the ideal of "it will last for long and be prosperous". But the ruler's faith in the myth of heaven's will is for real. Sima Qian's selected narration fully showed us why the Chinese history is the mythological history.

In A Dream of Red Mansions, a novel by Cao Xueqin, the correspondence between the imperial seal and the supreme ruler was replaced by the relationship between Jia Baoyu, the hero, and his Tongling Jade. Description of the Jade's functions was more clear now than in the Qin and Han dynasties, i.e. its three mysterious functions were inscribed on the back of Tongling Jade: "first, drive away the evil spirits; second, heal chronic diseases; third, know the weal and woe.”8

Cao was truly the inheritor of the essence of Chinese jade culture. In the "third, know the weal and woe", i.e. the religious function of foreseeing the future, Jia Baoyu's Tongling Jade had surpassed the First Emperor of Qin's imperial jade seal, which fully showed the continuity of jade religion's mythological beliefs from the Neolithic Age to the last dynasty of the feudal society. People in the age of the First Emperor of Qin firmly believed that the jade seal can adequately represent the heaven's will to justify the emperor's ruling, which was the national belief, so the nation’s highest orders should be issued and published in the particular way of “胥书 (meaning: documents sealed by the imperial jade seal)"; people in the age of Cao Xueqin still believed that jade articles can “通灵 (tong ling, meaning: psychic )", i.e. relate to gods, which was a typical mythological function, while it was folk belief that Tongling Jade can protect its wearer's safety. Both the national belief represented by the king and the folk belief represented by the common people are the heritage of the great tradition of jade beliefs' culture embodied in the little tradition of Chinese characters. The historical records and the literary works of Chinese civilization, from different perspectives, reflected the same potential dominance of pre-state pre-historical jade beliefs in the coding and decoding of cultural texts' construction.

Up to now, only a few mythologists or philosophers pay enough attention to and do enough research on

\footnotetext{
7 Tang, Rongzuo. “On Jade” (Citing On the Imperial Seal). Guidance to Appraising the Ancient Jade. Edi. Song, Tibing; Li Nahua. Beijing: Beijing Yan Shan Press, 1998, p.158.

${ }^{8}$ Cao, Xueqin. A Dream of Red Mansions. Vol. 8 of the annotated version. Beijing: Beijing Normal University Press, 1987, p. 154.
} 
the relationships between mythology and politics and ideology. The relatively new works on this topic is a book published in 2002: Thinking Through Rituals: Philosophical Perspectives. The editor of these collected papers is Kevin Schilbrack, a philosophical professor with the education background in a seminary. In it, the 9th paper is Myths and Ideology, whose author is Christopher Flood, famous English contemporary political theorist, who concluded his paper as: "we need to demystify political mythological theories. Mythological creations filled up the daily activities of political interactive texts. There's no need to regard myths as some special ways of expression or involve beliefs in a kind of insensible psychopathic mythology. Mythological creation is no rare matter or mistake. It's nothing less than a way to make the political events easy to comprehend by way of ideological beliefs. After a long time, some stories seemed quite important in a social group; while, some others soon disappeared. But the creation and re-creation of mythological narrations is permanent in the political life." ${ }^{\text {Th }}$ The Mythological Concepts Determinism put forward in this paper is to highlight the prototype function of mythological concepts to the ideology. Once the prototype of certain cultural community is revealed, the evolvement track of its historical cultural texts and the permanent operative relations between coding and re-coding will emerge. The contemporary theme-human beings' "myths to live by" (the tile of Joseph Campbell's works) will also be fully understood.

\section{Chapter Four Conclusion: Explore the Determinative Elements in Culture}

This paper, from the perspective of solving the motives of human behaviors, refers to and discusses on the theoretic proposal of Mythological Concepts Determinism, and advocates the integrated research view of ideological history, history of ideas and cultural history. Historical events do not exist in isolation. Can we reproduce the conceptual elements dominating the rulers by exploring the historical causality? In his book On the Origin of Thought written in 1909, Ball La Fog, the French Marxist at the beginning of 20th century, talked about the economy determinism popular at that time. This book was also translated as Karl Marx's Economy Determinism, which is famous for criticizing the idealist theory of the origin of thought. The book has six parts, i.e. "Karl Marx’s Historical Method”, "The Origin of Abstract Thought”, "The Origin of Justice Thought”, "The Origin of Good Thought”, “The Origin and Development of Soul Thought”, "Faith in God” etc. La Fog used the mythological stories as his materials, to illustrate the origin and evolution of justice, good and other moral concepts, and argue the fundamental ethical view that virtues originate from economic environment. A big gap was left between the Economy Determinism and Mythological Concepts Determinism. The task of bridging this gap was accomplished by the 20th-century mythological studies. From Onians' mythological research on the origin of the western thoughts to Walter Burkert's relevant research on the old Greek rituals and mythological concepts, we can see the breakthroughs of several generations' top scholars in solving this difficult problem. On the basis of former scholars' achievements, I relate to the proposal of Mythological Concepts Determinism in this paper from the theoretic perspective, hoping to evoke further discussion and argumentation.

Karl, a contemporary English historical theorist, defined "determinism” as:

It is a kind of faith, believing that every event results from one or several reason and it won't happen in a different way unless the reason or something of the reason changes. Determinism is not something about history, but about all human beings' behaviors. People’s behaviors have no reasons, so they are not determined.

${ }^{9}$ Schilbrack, Kevin. Thinking Through Rituals. London and New York: Routledge, 2002, p.188 . 
Such people are also something abstract as those individuals outside the society that we talked about in the last lecture. Bob’s idea that "everything is possible in human beings' affairs” is either nonsense or wrong. In daily life, no one believes or can believe this. The principle that every event has a reason is the precondition of the ability to understand what's happening around us. ${ }^{10}$

I need to add to that human being's first beliefs do not come from reading or teaching the Bible in churches, but from all cultures and civilizations in the prehistoric age. The Mythological Concepts Determinism can become the common and effective research approach for humanities and social sciences only after making clear how the core concepts of a culture come into being from the perspective of the great tradition.

${ }^{10}$ Carr, Edward Hallett. What Is History. Trans. Wu, Zhucun. Beijing: The Commercial Press, 1981. Pp.100-101 